\title{
Profil Trauma Toraks di Ruang Rawat Inap Bedah RSUD Gambiran Periode Maret 2017 - Maret 2018
}

\author{
Christophorus N. Handoyo ${ }^{1 *}$, Edy Supriyanto ${ }^{2}$ \\ Instalasi Bedah RSUD Gambiran Kediri, ${ }^{1,2}$ \\ Jalan Kapten Tendean No.16, Pakunden, Kota Kediri \\ *e-mail: Christ_thefollower@ymail.com
}

\begin{abstract}
Abstrak
Trauma menjadi masalah kesehatan masyarakat yang utama di seluruh dunia karena dikaitkan dengan morbiditas dan mortalitas yang tinggi baik di negara maju dan berkembang. Trauma toraks terjadi hampir pada $50 \%$ dari semua kecelakaan dan menjadi penyebab penting kematian. Penelitian ini bertujuan untuk mendapatkan data tentang trauma toraks di ruang rawat inap bedah RSUD Gambiran Kediri periode Maret 2017 - Maret 2018. Jenis penelitian ini adalah deskriptif retrospektif dengan menggunakan semua jumlah kasus trauma torak sebanyak 31 pasien dari 545 pasien trauma bedah yang membutuhkan rawat inap. Hasil penelitian mendapatkan kasus trauma toraks paling banyak ialah fraktur iga $(29 \%)$ yang terjadi pada jenis kelamin laki-laki (93,5\%) dan kelompok usia 46-60 tahun (35,5\%). Penyebab tersering adalah kecelakaan lalu lintas $(80,6 \%)$ sedangkan penanganan paling banyak dilakukan ialah penanganan konservatif (100\%). Durasi rawat inap pasien trauma toraks paling sering sekitar 1-3 hari $(58,1 \%)$ dengan hasil akhir trauma toraks yang didapat umumnya sembuh $(93,6 \%)$.
\end{abstract}

Kata kunci: trauma, trauma toraks, fraktur iga

\section{Profile of Thoracic Trauma in Surgery Ward at RSUD Gambiran in the Period of March 2017 - March 2018}

\begin{abstract}
Trauma is a significant worldwide health problem because it is associated with high morbidity and mortality for both developed and developing nations. Thoracic trauma occurs in almost $50 \%$ of all accident and is a leading cause of death. This study was aimed to obtain the profile of thoracic trauma in surgery unit of Gambiran General Hospital Kediri from March 2017 to March 2018. This was a retrospective descriptive study using all medical records of thoracic trauma. The results showed that there were 31 cases of thoracic trauma out of 545 inpatient trauma cases. The majority of cases is rib fractured (29\%) occured in males $(93,5 \%)$ and age group 46-60 years old (35,5\%). The most common cause was traffic accidents(80,6\%) meanwhile most of treatment performed was conservative treatment $(100 \%)$. The most common of hospitalization's duration was about 1 to 3 days with the outcome of most thoracic trauma was healed $(93,6 \%)$.
\end{abstract}

Keywords: trauma, thoracic trauma, rib fractured 
Profil Trauma Toraks di Ruang Rawat Inap Bedah RSUD Gambiran Periode...

Christophorus N. Handoyo1*, Edy Supriyanto2

\section{PENDAHULUAN}

Sejak lama trauma merupakan suatu masalah medis yang terabaikan (neglected disease) oleh para dokter, masyarakat, maupun pemerintah di seluruh dunia. Pada kenyataannya, trauma ialah kejadian yang bersifat holistik dan menyebabkan hilangnya produktivitas seseorang (Sjamsuhidajat and de Jong, 2010). Trauma adalah penyebab utama morbiditas dan mortalitas di seluruh dunia sebagai hasil dari teknologi yang cepat dan meningkat tingkat kejahatan di masyarakat (A)koudmani et al, 2012).

Trauma toraks terjadi hampir pada $50 \%$ dari semua kecelakaan. Trauma toraks berperan pada $25 \%$ dari semua kematian akibat trauma dan $25 \%$ lainnya berkontribusi pada morbiditas dan mortalitas (Chiragkumar et al, 2014).

Insiden dari trauma toraks di Amerika adalah 12 orang bagi setiap 1000 orang penduduk tiap harinya, dan $20-25 \%$ kematian yang disebabkan oleh trauma adalah disebabkan oleh trauma toraks. Trauma toraks diperkirakan bertanggung jawab atas 16,000 kematian tiap tahunnya di Amerika. Di Indonesia sendiri kejadian kecelakaan lalu lintas meningkat dalam jumlah maupun jenisnya dengan perkiraan angka kematian dari 5,1 juta pada tahun 1990 menjadi 8,4 juta pada tahun 2020 atau meningkat sebanyak 65\% (Farina et al,
2012). Di RSUP Prof. Dr. R. D. Kandou Manado didapatkan 120 kasus trauma toraks pada tahun 2014 hingga Juni 2016 (Kevin et al, 2016). Jumlah kematian akibat kecelakaan lalu lintas di RSUP Prof. Dr. R. D. Kandou Manado berjumlah 85, dan yang meninggal akibat trauma toraks berjumlah 7 orang (Jessica et al, 2015).

Trauma toraks adalah penyebab penting kematian. Banyak pasien dengan trauma toraks meninggal setelah sampai di rumah sakit. Namun banyak dari kematian ini dapat dicegah dengan diagnostik yang cepat dan pengobatan segera mungkin. Hipoksia, hiperkarbia, dan asidosis sering merupakan hasil dari trauma toraks. Hipoksia jaringan terjadi akibat ketidakmampuan distribusi oksigen ke jaringan karena hipovolemi (perdarahan), ketidakcocokan ventilasi atau perfusi paruparu (contusio, hematom dan kolaps alveolus), dan perubahan tekanan intra torakal (tension pneumotoraks dan open pneumotoraks). Hipoperfusi inilah yang menyebabkan terjadinya asidosis metabolik. Hiperkarbi dengan asidosis respiratorik sering dikarenakan karena ventilasi yang tidak memadai yang disebabkan oleh perubahan tekanan intra torakal dan penurunan kesadaran (American College of Surgeons Committee, 2012). 
Keadaan Bedah toraks akut dibagi menjadi tiga, yaitu : Trauma tumpul dan trauma tajam, trauma tembus dan tidak tembus, flail chest (Puruhito, 2013). Cedera dada tumpul adalah salah satu masalah paling penting dalam praktik sehari-hari terutama karena meningkatnya insiden kecelakaan lalu lintas. Dinding dada dan organ-organ dalam rongga dada adalah lokasi yang paling sering terkena trauma tumpul. Meskipun sebagian besar fraktur iga adalah ringan dan dapat ditindaklanjuti tanpa rawat inap, trauma terbatas pada rongga toraks itu sendiri dapat menyebabkan perubahan patofisiologis yang mendalam, yang dapat berakibat fatal jika tidak segera diobati (Liman et al, 2003).

Trauma tembus toraks mencapai 1$13 \%$ dari jumlah total trauma toraks. $85 \%$ dari trauma tembus toraks ini dapat dikelola, baik dengan observasi atau drainase pleura, sementara hanya $15-30 \%$ kasus yang memerlukan intervensi bedah untuk trauma pada organ toraks yang dapat berakibat fatal (Paci et al, 2006).

Penelitian ini dibuat bertujuan untuk mendapatkan untuk mengetahui profil trauma toraks di ruang rawat inap bedah RSUD Gambiran Kediri periode Maret 2017 - Maret 2018. Penelitian ini belum pernah dilakukan di RSUD Gambiran kota Kediri, sehingga hasil dari penelitian ini dapat memberikan manfaat bagi pihak terkait.

\section{METODE PENELITIAN}

Jenis penelitian ini adalah penelitian deskriptif yang bersifat retrospektif pada pasien trauma toraks di RSUD Gambiran Kota Kediri. Lokasi penelitian dipilih RSUD Gambiran kota Kediri karena, RSUD Gambiran kota Kediri merupakan pusat rujukan daerah karesidenan Kediri. RSUD Gambiran kota Kediri adalah rumah sakit tipe B milik pemerintah kota Kediri, yang secara historis dibangun oleh Belanda pada tahun 1875 dan muklai dikembangkan pada tahun 1928. RSUD Gambiran kota Kediri memiliki 39 dokter spesialis, 21 dokter umum, 20 struktural, 320 perawat, 89 bidan, 147 paramedis non perawat dan 349 non medis. Subjek penelitian ialah semua data rekam medik pasien trauma toraks diruang rawat inap bedah RSUD Gambiran Kota Kediri periode Maret 2017 - Maret 2018. Penelitian ini dilakukan selama bulan Maret 2018 - Juni 2018 setalah mendapatkan persetujuan plt Direktur, kepala bidang pelayanan, kepala DIKLAT dan kepala rekam medis RSUD Gambiran kota Kediri. Variabel penelitian yang diambil dari data rekam medik yaitu: Jenis kelamin, usia, faktor penyebab, jenis trauma toraks, penanganan, durasi perawatan, dan hasil akhir perawatan. Semua informasi yang 
Profil Trauma Toraks di Ruang Rawat Inap Bedah RSUD Gambiran Periode...

Christophorus N. Handoyo1*, Edy Supriyanto2

dkumpulkan dijamin kerahasiaannya oleh

peneliti, hanya kelompok data tertentu

yang akan dilaporkan pada hasil riset.

Analisis data menggunakan metode

analisis data kuantitatif. Data kuantitatif yang didapat masih berbentuk dataset yang masih mentah. Data set yang mentah dikonversi menjadi lebih matang. Hal ini dilakukan dengan cara clearing, yaitu membersihkan data mentah yang tidak relevan untuk diolah. Setelah data yang bernilai sudah didapatkan, selanjutnya diolah dengan menggunakan software SPSS versi 24. Pada tahap ini peneliti juga memeriksa kualitas data seperti adakah data missing atau error.

\section{HASIL PENELITIAN}

Berdasarkan hasil penelitian yang telah dilakukan dengan cara mengambil data rekam medik pasien trauma toraks di ruang rawat inap bedah RSUD Gambiran Kota Kediri periode Maret 2017 - Maret 2018. Selama periode studi, total pasien trauma bedah yang dirawat inap berjumlah 545 orang dan 31 orang dari total pasien trauma yang dirawat inap merupakan pasien dengan trauma toraks. Sehingga, kasus trauma toraks didapatkan sebanyak 5,7\% dari semua kasus trauma bedah yang membutuhkan rawat inap.

Tabel 1. Statistik Descriptif

\begin{tabular}{cccccc}
\hline & N & Minimum & Maximum & Mean & Std. Deviation \\
\hline Jenis Kelamin & 31 & 1 & 2 & 1,06 & 0,250 \\
Umur & 31 & 8 & 65 & 41,19 & 17,751 \\
Lama Dirawat & 31 & 1 & 16 & 4,42 & 4,233 \\
Tindakan & 31 & 2 & 2 & 2,00 & 0,000 \\
Diagnosa & 31 & 1 & 6 & 2,68 & 1,423 \\
Keluar Rumah Sakit & 31 & 1 & 4 & 1,16 & 0,638 \\
Penyebab & 31 & 1 & 4 & 1,35 & 0,839 \\
\hline Valid N (listwise) & 31 & & & & \\
\hline
\end{tabular}

Distribusi trauma toraks berdasarkan jenis kelamin dapat diamati pada Tabel 2.

Tabel 2. Distribusi Trauma Toraks Berdasarkan Jenis Kelamin

\begin{tabular}{cccc}
\hline \multirow{2}{*}{ Tahun } & \multicolumn{3}{c}{ Jumlah Kasus (\%) } \\
\cline { 2 - 4 } & Laki-laki & Perempuan & Total \\
\hline 2017 & $21(91,3 \%)$ & $2(8,7 \%)$ & $23(76,7 \%)$ \\
2018 & $8(100 \%)$ & $0(0 \%)$ & $8(23,3 \%)$ \\
\hline Total & $\mathbf{2 9 ( 9 3 , 5 \% )}$ & $\mathbf{2 ( 6 , 5 \% )}$ & $\mathbf{3 1 ( 1 0 0 \% )}$ \\
\hline
\end{tabular}

Dari total 31 orang pasien, pada lakilaki didapatkan sebanyak 29 orang (93,5\%) dan pada perempuan didapatkan sebanyak 2 orang (6,5\%). Distribusi trauma toraks berdasarkan kelompok umur disajikan pada Tabel 3. 
Tabel 3. Distribusi trauma toraks berdasarkan kelompok umur

\begin{tabular}{ccc}
\hline Kelompok Umur & Jumlah Kasus (Orang) & Presentase (\%) \\
\hline $0-15$ tahun & 5 & 16,1 \\
$16-30$ tahun & 7 & 22,6 \\
$36-45$ tahun & 4 & 12,9 \\
$46-60$ tahun & 11 & 35,5 \\
$>60$ tahun & 4 & 12,9 \\
\hline Total & $\mathbf{3 1}$ & $\mathbf{1 0 0}$ \\
\hline
\end{tabular}

Berdasarkan umur dari total 31 orang pasien, didapatkan kelompok umur antara 0-15 tahun sebanyak 5 orang $(16,1 \%)$, antara 16-30 tahun sebanyak 7 orang $(22,6 \%)$, antara 36-45 tahun sebanyak 4 orang (12,9\%), antara 46-60 tahun sebanyak 11 orang (35,5\%), dan 60 tahun ke atas sebanyak 4 orang (12,9\%). Distribusi trauma toraks berdasarkan faktor penyebab dapat dilihat pada Tabel 4.

Tabel 4. Distribusi trauma toraks berdasarkan faktor penyebab

\begin{tabular}{lcc}
\hline \multicolumn{1}{c}{ Faktor Penyebab } & Jumlah Kasus (orang) & Presentase (\%) \\
\hline Kecelakaan lalu lintas & 25 & 80,6 \\
Kecelakaan kerja & 3 & 9,7 \\
Perkelahian & 2 & 6,5 \\
Luka Tembak & 1 & 3,2 \\
\hline Total & $\mathbf{3 1}$ & $\mathbf{1 0 0}$
\end{tabular}

Berdasarkan total 31 orang pasien

trauma toraks maka didapatkan penyebab trauma paling banyak disebabkan oleh kecelakaan Ialu lintas (kebanyakan pasien menggunakan sepeda motor) sebanyak 25 orang $(80,6 \%)$, lalu yang disebabkan kecelakaan kerja sebanyak 3 orang $(9,7 \%)$, akibat perkelahian seperti pukulan benda keras ataupun tendangan sebanyak 2 orang (6,5\%), dan terakhir yang disebakan luka tembak oleh senapan angin sebanyak 1 orang $(3,2 \%)$. Distribusi trauma toraks berdasarkan jenisnya ditampilkan pada Tabel 5.

Tabel 5. Distribusi trauma toraks berdasarkan jenisnya

\begin{tabular}{lcc}
\hline \multicolumn{1}{c}{ Jenis Trauma Toraks } & $\begin{array}{c}\text { Jumlah Kasus } \\
\text { (orang) }\end{array}$ & Persentase (\%) \\
\hline Contusio pulmonum & 7 & 22,6 \\
Fraktur iga & 9 & 29,0 \\
Hematotoraks & 7 & 22,6 \\
Pneumotoraks & 5 & 16,1 \\
Trauma Toraks Penetrans & 1 & 3,2 \\
Trauma Tumpul Toraks & 2 & 6,5 \\
\hline Total & 31 & 100 \\
\hline
\end{tabular}


Profil Trauma Toraks di Ruang Rawat Inap Bedah RSUD Gambiran Periode...

Christophorus N. Handoyo1*, Edy Supriyanto2

Dari jumlah keseluruhan sebanyak

31 kasus trauma toraks, didapatkan sebanyak 1 orang $(3,2 \%)$ mengalami trauma toraks penetrans akibat luka tembak. 2 orang $(6,5 \%)$ mengalami trauma tumpul toraks, 5 orang $(16,1 \%)$ mengalami pneumotoraks, kemudian yang mengalami hematotoraks sebanyak 7 orang $(22,6 \%)$, lau yang mengalami contusio pulmonum sebanyak 7 orang $(22,6 \%)$, dan yang mengalami fraktur iga sebanyak 9 orang (29,0\%). Tabel 6 disajikan distribusi trauma toraks berdasarkan cara penanganannya

Tabel 6.Distribusi Trauma Toraks Berdasarkan

\begin{tabular}{ccc}
\multicolumn{3}{c}{ Cara Penanganan } \\
Cara Penanganan & $\begin{array}{c}\text { Jumlah } \\
\text { Kasus } \\
\text { (orang) }\end{array}$ & $\begin{array}{c}\text { Persentase } \\
\mathbf{( \% )}\end{array}$ \\
\hline Konservatif & 31 & 100 \\
Operatif & 0 & 0 \\
\hline Total & $\mathbf{3 1}$ & $\mathbf{1 0 0}$ \\
\hline
\end{tabular}

Dari total 31 orang pasien, trauma toraks yang ditangani secara konservatif sebanyak 31 orang (100\%) dan trauma toraks yang ditangani dengan metode operatif tidak ada (0\%). Tabel 7 menunjukkan distribusi trauma toraks berdasarkan durasi perawatan.

Tabel 7. Distribusi trauma toraks berdasarkan durasi perawatan

\begin{tabular}{ccc}
\hline $\begin{array}{c}\text { Durasi } \\
\text { perawatan }\end{array}$ & $\begin{array}{c}\text { Jumlah } \\
\text { Kasus } \\
\text { (orang) }\end{array}$ & $\begin{array}{c}\text { Persentase } \\
\text { (\%) }\end{array}$ \\
\hline 1-3 hari & 18 & 58,1 \\
4-7 hari & 5 & 16,1 \\
8-10 hari & 4 & 12,9 \\
>10 hari & 4 & 12,9 \\
\hline Total & $\mathbf{3 1}$ & $\mathbf{1 0 0}$ \\
\hline
\end{tabular}

Dari jumlah keseluruhan sebanyak 31 pasien rawat inap, didapatkan pasien paling banyak dirawat dalam rentang 1-3 hari yaitu sejumlah 18 orang $(58,1 \%)$. Sedangkan pasien yang dirawat dalam rentang 4-7 hari sebanyak 5 orang (16,1\%). Pasien yang dirawat dalam rentang 8-10 hari sebanyak 4 orang $(12,9 \%)$ dan pasien yang dirawat lebih dari 10 hari yaitu juga sejumlah 4 orang $(12,9 \%)$ dengan durasi perawatan paling lama selama 16 hari. Distribusi trauma toraks berdasarkan hasil akhir perawatan disajikan pada Tabel 8.

Tabel 8. Distribusi trauma toraks berdasarkan hasil akhir perawatan

\begin{tabular}{ccc}
\hline $\begin{array}{c}\text { Hasil Akhir } \\
\text { perawatan }\end{array}$ & $\begin{array}{c}\text { Jumlah } \\
\text { Kasus } \\
\text { (orang) }\end{array}$ & $\begin{array}{c}\text { Persentase } \\
\text { (\%) }\end{array}$ \\
\hline Sembuh & 29 & 93,6 \\
Pulang Paksa & 0 & 0 \\
Dirujuk & 1 & 3,2 \\
Meninggal Dunia & 1 & 3,2 \\
\hline Total & $\mathbf{3 1}$ & $\mathbf{1 0 0}$ \\
\hline
\end{tabular}

Dari total 31 orang pasien trauma toraks yang dirawat, didapatkan sebanyak 29 orang $(93,6 \%)$ dinyatakan sembuh pada hasil akhir perawatan. Pasien yang dirujuk di rumah sakit lain karena membutuhkan fasilitas yang lenbih memadai berjumlah 1 orang $(3,2 \%)$ dan terdapat 1 orang $(3,2 \%)$ yang meninggal dunia di akhir perawatan. Selain itu, dari keseluruhan kasus trauma toraks, tidak didapatkan pasien yang pulang atas permintaannya sendiri. 


\section{PEMBAHASAN}

Dari hasil penelitian trauma toraks di RSUD Gambiran Kota Kediri periode Maret 2017 - M aret 2018, berdasarkan distribusi jenis kelamin didapatkan bahwa pasien pada laki-laki (93,5\%) lebih banyak daripada perempuan (6,5\%). Hal ini sesuai dengan penelitian oleh Mario et al bahwa aktivitas laki-laki lebih tinggi daripada perempuan dalam semua kriteria yang digunakan. Tingginya tingkat aktivitas lakilaki daripada perempuan dikarenakan banyak hal, contohnya laki-laki bekerja lebih banyak diluar rumah daripada di dalam rumah serta banyak yang berkaitan dengan kendaraan contohnya sopir ojek, sopir truk, sopir travel, sopir bus. Selain itu laki-lakimemiliki kecenderungan lebih tidak safety saat mengendarai sepeda motor daripada perempuan (Jasa Raharja, 2009).

Berdasarkan kelompok usia yang tertinggi adalah kelompok usia antara 4660 tahun (35,5\%), diikuti oleh kelompok usia 16-30 tahun $(22,6 \%), 0-15$ tahun $(16,1 \%),>60$ tahun $(12,9 \%), 36-45$ tahun (12,9\%). Kelompok usia 46 - 60 tahun merupakan yang terbanyak. Kelompok usia ini merupakan kelompok usia yang produktif. Dari data rekam medis yang didaptakan, kelompok usia ini semuanya merupakan pekerja. Sehingga di kelompok ini sangat tinggi aktivitas dan mobilitasnyayang berhubungan dengan pekerjaannya. Berdasarkan data dari Mabespolri, usia terbanyak yang mengalami kecelakaan lalu intas adalah kelompok usia 16 -30 tahun (Korlantas Polri, 2013). Namun belum ada data lebih lanjut mengenai jumlah kelompok usia yang terkena trauma toraks.

Berdasarkan penyebabnya, trauma toraks paling banyak disebabkan oleh kecelakaan Ialu lintas $(80,6 \%)$. Selanjutnya diikuti oleh kecelakaan kerja $(9,7 \%)$, akibat perkelahian (6,5\%), dan terakhir yang disebakan luka tembak (3,2\%). Kecelakaan lau lintas masih menjadi penyebab utama terjadinya trauma toraks, dan kecelakaan yang terjadi pada penderita semuanya dikarenakan saat mengendarai sepeda motor. Dalam laporan Korlantas Polri 2013, sepeda motor terlibat paling banyak dalam jumlah kecelakaan, yaitu 119.560 kejadian dari total 168.183 kejadian. Tentunya hal ini berkaitan dengan masyarakat Indonesia yang mayoritas masih menggunakan sepeda motor sebagai kendaraan utama (Badan Pusat Statistik, 2017). Selain banyaknya yang mengendarai sepeda motor, kecelakaan lalul lintas dipengaruhi juga oleh kepatuhan pengemudinya. Seperti kecepatan saat mengendarai sepeda motor, kepatuhan terhadap ramburambu lalu lintas dan kepadatan lalu lintasnya sendiri (Jasa Raharja, 2009). Berdasarkan penelitian ini, trauma toraks 
Profil Trauma Toraks di Ruang Rawat Inap Bedah RSUD Gambiran Periode...

Christophorus N. Handoyo1*, Edy Supriyanto2

oleh karena mengendarai mobil lebih jarang terjadi dibandingkan mengendarai sepeda motor. Hal ini mungkin berkaitan dengan mobil yang lebih perangkat keselamatan yang lebih baik dibandingkan dengan sepeda motor.

Dari jumlah keseluruhan sebanyak 31 kasus trauma toraks, didapatkan trauma toraks penetrans akibat luka tembak sebanyak 1 orang $(3,2 \%)$, trauma tumpul toraks sebanyak 2 orang $(6,5 \%), 5$ orang $(16,1 \%)$ yang mengalami pneumotoraks, 2 diantaranya mengalami tension pneumotoraks, 7 orang $(22,9 \%)$ mengalami hematotoraks, kemudian yang mengalami contusio pulmonum sebanyak 7 orang $(22,9 \%)$ dan fraktur iga sebanyak 9 orang $(29,0 \%)$. Pada beberapa pasien ada yang memiliki lebih dari satu diagnosa, diagnosa dibuat bedasarkan keadaan yang menjadi masalah utama (diagnosa primer) pasien saat sedang berada di ruangan rawat inap. Trauma tumpul toraks dapat memengaruhi satu atau seluruh komponen pada dinding dada dan kavum toraks (M arc et al, 2017). Fraktur iga merupakan jumlah terbanyak dalam penelitian ini. Tulang Iga yang merupakan pelindung dari organ - organ dalam rongga toraks, baik benturan yang terjadi dari depan, lateral maupun belakang. Lee et al (2003) dalam penelitiannya mengatakan bahwa patahnya tulang iga tidak dipengaruhi oleh umur, tinggi badan, berat badan, kedalaman dan lebar dari tulang iga.Tidak ditemukan adanya hubungan antara impact responses toraks dan umur.Wanita memiliki kekakuan tulang iga yang lebih rendah $(267 \pm 150 \mathrm{kN} / \mathrm{m})$ dibandingkan dengan pria $(476 \pm 324 \mathrm{kN} / \mathrm{m})$ pada benturan dari depan. Hal ini menyebabkan Maximum deflection dan compression ratio pada wanita jauh lebih tinggi dibandingkan dengan pria dengan impact energy yang sama (Lee et al, 2003). Pada sembilan pasien fraktur iga pada penelitian ini, semuanya disebabkan oleh kecelakaan lalu lintas, besarnya energi hantaman pada toraks yang melebihi kekuatan dan kelenturan dari tulang iga akan menyebabkan terjadinya fraktur iga. Tujuh orang pasien mengalami contusio pulmonum atau memar paru. Hal ini berkaitan dengankekuatan dan kelenturan tulang iga yang menjadi pelindung bagi organ-organ dalam rongga toraks.Tulang Iga anak-anak tidak sama dengan tulang iga orang dewasa, tulang iga anak-anak lebih lentur dibandingkan orang dewasa (Puruhito, 2013). Ketujuh pasien ini merupakan dewasa muda (>23 tahun) dan semuanya mengalami patah pada tulang iga pada sisi yang sama dengan terjadinya memar paru.Tujuh orang mengalami hematotoraks, 2 orang yang masuk dalam kriteria masif hematotoraks. Dari 7 orang 
pasien, 4 diantaranya terdapat fraktur pada iga. Masif hemotoraks adalah keadaan lebih dari 800 cc darah dalam 1 cavum toraks, dan merupakan indikasi untuk dilakukan torakotomi terbuka (Puruhito, 2013). Pada kedua pasien ini tidak dilakukan karena belum adanya operator yang dapat melakukan torakotomi terbuka. Ketujuh pasien hematotoraks ini dilakukan tindakan pemsangan water seal drainage. Lima orang pasien dengan diagnosa pneumotoraks, dua diantaranya mengalami tension penumotoraks. Pada pasien dengan tension penumotoraks dibutuhkan segera pemasangan kontra ventil sebagai tindakan awal penyelamatan jiwa. Kedua pasien ini telah dilakukan tindakan pemasangan kontra ventil sebagai usaha penyelamatan jiwa, lalu dilanjutkan dengan pemsangan water seal drainage dengan hisapan kontinu. Dua orang mengalami trauma tumpul toraks. Diagnosa trauma tumpul toraks dibuat saat terjadi trauma karena benda tumpul pada dinding trauma toraks dan tidak komplikasi yang menyertainya (Mancini, 2017). Satu orang mengalami luka tembak senapan angin di dada.

Lamanya perawatan dalam hari secara keseluruhan pada 31 pasien yang diteliti adalah 137 hari, sehingga memiliki nilai rata-rata 4 hari perawatan. Dari total 31 orang pasien, semuanya ditangani secara konservatif (100\%) dan tidak ada yang ditangani dengan metode operatif. Sebanyak 31 pasien tersebut 29 orang (96,7\%) pulang dalam keadaan yang baik, lorang dengan contusio pulmonum kanan dan fraktur iga 4-7 sebelah kanan dirujuk ke fasilitas yang lebih memadai agar mendapatkan penanganan yang lebih baik.Terdapat 1 pasien $(3,3 \%)$ yang meninggal. Pasien yang meninggal adalah pasien dengan hematotoraks masif sinistra dan contusio pulmonum kanan serta fraktur iga 4-8. Hasil penelitian ini menunjukan bahwa dalam penanganan trauma toraksdapat dilakukan tindakantindakan bedah dasar dalam upaya penyelamatan dengan prosedur tindakan penyelamatan (life saving procedure) yang apabila segera dilakukan lebih dari $90 \%$ pasien dalam penelitian ini dapat teratasi fase kritisnya. Pasien pada penelitian ini tidak ada yang dilakukan tindakan operasibesar (Ex: torakotomi terbuka, pemasangan costafix SHAPP $\AA$ ), karena tidak memenuhi kriteria Indikasi operasi, belum adanya instrumen untuk operasi torakotomi terbuka dan belum adanya dokter spesialis di bidang terkait (Puruhito, 2013).

Penelitian ini menggunakan rekam medis sebagai data penelitian, sehingga peneliti tidak tahu kondisi paseien yang sebenarnya. Pencatatan dapat kurang 
Profil Trauma Toraks di Ruang Rawat Inap Bedah RSUD Gambiran Periode...

Christophorus N. Handoyo1*, Edy Supriyanto2

akurat karena tidak sesuai dengan icd 10

ataupun karena kesalahan penulisan.

Namun penelitian yang menggunakan total

sampel ini dapat mempresentasikan

seutuhnya profil di RSUD Gambiran kota

Kediri.

\section{KESIM PULAN}

Kasus trauma toraks didapatkan sebanyak $5,7 \%$ dari semua kasus trauma bedah yang membutuhkan rawat inap. Jenis kelamin penderita trauma toraks di RSUD Gambiran kota Kediri paling banyak adalah laki-laki. Penderita trauma toraks di RSUD Gambiran kota Kediri paling banyak adalah Kelompok usia 46-60 tahun. Kecelakaan lalu lintas menjadi penyebab utama terjadinya trauma toraks di RSUD Gambiran kota Kediri. Fraktur Iga merupakan jenis dari trauma toraks paling banyak di RSUD Gambiran kota Kediri. Rata-rata lamanya rawat inap pasien dengan trauma toraks di RSUD Gambiran kota Kediri adalah 4 hari. Pasien trauma toraks di RSUD Gambiran kota Kediri tidak ada yang dilakukan operasi besar, dan jumlah pasien yang pulang sembuh berjumlah $93,6 \%$.

\section{DAFTAR PUSTAKA}

Al-koudmani I, Darwish B, Al-kateb K, Taifour Y, 2012. Chest trauma experience over eleven year period at Al-Mouassat University Teaching Hospital- Damascus: a retrospective review of 888 cases. J Cardiothorac Surg. 2012: 7:35

American College of Surgeons Committee on Trauma, 2012. Advanced Trauma Life Support 9th ed. 633 N. Saint Clair Street, Chicago. $p$ 95-96

Badan Pusat Statistik, 2017. Jumlah Kendaraan Bermotor (Unit).

Chiragkumar LP, Mukesh DK, Upendra A, Jay $P, 2014$. Profile of Chest Trauma In A Teaching Hospital. National Journal of Medical Research. 2014. p 79-81

Farina A, Esti W, Budi R, Fristika M, Novi I, et al., 2012. Petunjuk Teknis Pemeriksaan Kesehatan Faktor Risiko Kecelakaan Lalu Lintas Bagi Pengemudi Angkutan Umum pada Situasi Khusus. Kemenkes RI. Jakarta: 1 - 2

Jessica R, Erwin G, and James F, 2015. Pola Cedera Toraks pada Kecelakaan Lalu Lintas yang Menyebabkan Kematian di bagian Forensik dan Medikolegal RSUP Prof. Dr. R.D. Kandou Periode Januari 2013Januari 2014. Jurnal Biomedik. 7(1): $42-47$

Lee JB, Begeman PC, Yang KH, and King Al, 2003. Biomechanical Properties ofThe Male and Female Chest Subjected to Frontal and Lateral Impacts. IRCOBI Conference, Lisbon. p: 242 - 245 
Liman ST, Kuzucu A, Tatepe Al, Ulasan GN, and Topcu S, 2003. Chest injury due to blunt trauma. European Journal of Cardio-Thoracic Surgery. 23(3): 374-378

Kevin G, Adrian T, and Elwin M, 2016. Pola trauma tumpul toraks non penetrans, penanganan, dan hasil akhir di Instalasi Rawat Darurat Bedah RSUP Prof. Dr. R.D. Kandou Manado periode Januari 2014 Juni 2016. Skripsi. Fakultas Kedokteran Universitas Sam Ratulangi, Manado

Korlantas Polri, 2013. Polantas Dalam Angka 2013. Jakarta, 9

Mancini MC, 2017. Blunt Chest Injury.https://emedicine.medsca pe.com

Marc DM, Ram N, Walter B, 2017.Rib fixation: Who, What, When?.BM J Journal. Volume 2 issue 1. http://tsaco.bmj.com

Mario RA, Cora LPA, Felipe FR, Fernando VS, MC da Silva, et al, 2007 Gender differences in leisuretime physical activity. International Journal Public Health. 52(1): 8-15

Paci M, Ferrari G, Annesi V, de Franco S, Guasti G, Sgarbi G, 2006. The role of diagnoctic VATS in penetrating thoracic injuries. World J Emerg Surg. 1: 30-31

Puruhito, 2013. Buku Ajar Primer IImu Bedah Toraks, Kardiak, dan Vaskular. Airlangga University Press, Surabaya. p 29-232
PT. Jasa Raharja, 2009. Kajian teknis tentang penilaian dampak keselamatanjalan (Road Safety Impact Assessment/ RSIA)

Sjamsuhidajat R and de Jong W, 2010. Buku Ajar Ilmu Bedah (3rd ed). Jakarta: EGC. $p$ 121-2, 502-6 